\title{
Management and response to treatment of Helicobacter pylori gastritis
}

\author{
St James's \\ University Hospital, \\ Leeds \\ Department of \\ Paediatrics \\ M J Mahony \\ J M Littlewood \\ Department of Pathology \\ J I Wyatt \\ Correspondence to: \\ Dr M J Mahony, \\ Paediatric Unit, \\ Limerick Regional Hospital, \\ Dooradoyle, \\ Limerick, \\ Republic of Ireland. \\ Accepted I March 1992
}

\author{
M J Mahony, J I Wyatt, J M Littlewood
}

\begin{abstract}
Gastritis associated with Helicobacter pylori was present in gastric biopsies from 24/95 (25\%) children and adolescents undergoing endoscopy for recurrent abdominal pain and upper gastrointestinal symptoms. $H$ pylori associated gastritis occurred mainly in older children (8-16 years) and was significantly associated with low socioeconomic class and a family history of peptic ulcer disease. Antral nodularity was a common endoscopic finding in $\boldsymbol{H}$ pylori positive children. Eighteen children, all over 5 years of age, were treated with tripotassium dicitratobismuthate (De-Nol) for two months and ampicillin for two weeks. In 12 children follow up gastric biopsies were obtained six weeks after completion of treatment. In 9/12 (75\%) children $H$ pylori was eradicated, and gastritis improved.
\end{abstract}

Colonisation of the stomach with Helicobacter (formerly Campylobacter) pylori is now firmly established as an important cause of chronic gastritis and peptic ulcer disease in adults. ${ }^{12}$ Several studies have also established a role for this organism in children with abdominal pain and upper gastrointestinal symptoms. ${ }^{3-5} \mathrm{We}$ prospectively evaluated the prevalence of $H$ pylori gastritis in children undergoing endoscopy for abdominal pain and upper gastrointestinal symptoms, and report here the clinical, socioenconomic, endoscopic and histopathological features, and the response to treatment. The systemic immune response to $H$ pylori was also studied in these children and has been reported separately. ${ }^{6}$

\section{Methods}

A prospective study was performed between July 1987 and July 1991 on consecutive children presenting with recurrent abdominal pain, protracted vomiting, haematemesis, and melaena. Patients with recurrent abdominal pain and protracted vomiting had symptoms of at least three months' duration. Ninety five children (51 females), age range 6 months to 16 years, median 10 years, were investigated by upper gastrointestinal endoscopy and mucosal biopsy. Endoscopy was performed using Olympus GIF P3, Olympus XP20, and Fujinon UGI PE paediatric endoscopes by two paediatrician endoscopists (MJM, JML). Intravenous sedation using diazepam $0.5-1 \mathrm{mg} / \mathrm{kg}$, maximum $25 \mathrm{mg}$, was used in 93 children; two children had endoscopy under general anaesthesia. At least two antral biopsies were taken from each child, and in 55 an additional antral biopsy specimen was taken for gastric urease (CLO test, Delta West).

Biopsy specimens were fixed in neutra buffered formalin and stained with haematoxylin and eosin for grading of gastritis and Giemsa for detection of $H$ pylori. ${ }^{7}$ All specimens were examined by one histopathogist (JIW). Gastritis was graded using the Sydney classification: briefly, this grades the degree of mononuclear cell infiltration, neutrophil infiltration, atrophy, and intestinal metaplasia in gastric biopsy specimens, each on a scale of $0-3$. In addition the intensity of $H$ pylori colonisation is assessed also on a scale of $0-3 .^{8}$

Treatment with tripotassium dicitratobismuthate (De-Nol, Brocades) and ampicillin was given to children over 5 years of age with $H$ pylori associated gastritis. Children with 'lymphocytic gastritis' were excluded. Eighteen children with $H$ pylori associated gastritis, aged 5-15, median 12.5 years, were treated with tripotassium dicitratobismuthate for two months, and ampicillin for the first two weeks of treatment. Tripotassium dicitratobismuthate dosage was $240 \mathrm{mg}$ twice daily in those over 10 years, and $120 \mathrm{mg}$ twice daily in those under 10 years. The ampicillin dose was $500 \mathrm{mg}$ four times a day in those over 10 , and $250 \mathrm{mg}$ four times a day in those under 10 years. Follow up antral biopsies were obtained six weeks after completion of treatment in 12/18 children and were assessed for eradication of $H$ pylori and severity of gastritis. For the purpose of comparing biopsy specimens taken before and after treatment the grades of mononuclear cell infiltration $(0-3)$ and neutrophil infiltration (0-3) were added to devise a gastritis score (range 0-6).

Bismuth concentrations were measured in whole blood at completion of tripotassium dicitratobismuthate treatment by hydride generation atomic absorption spectroscopy (Rooney Laboratories). ${ }^{9}$

Informed consent was obtained from the children's parents, and the study was approved by the hospital ethics committee of Leeds East Health Authority.

Statistical analysis was performed using Fisher's exact probability test, and Wilcoxon's signed pair test.

\section{Results}

Gastritis was present in antral biopsies from $25 / 95$ children $(26 \%)$. In 24 children $(25 \%)$, age range 9 months to 15 years, median 12.5 years, chronic gastritis was associated with $H$ pylori 


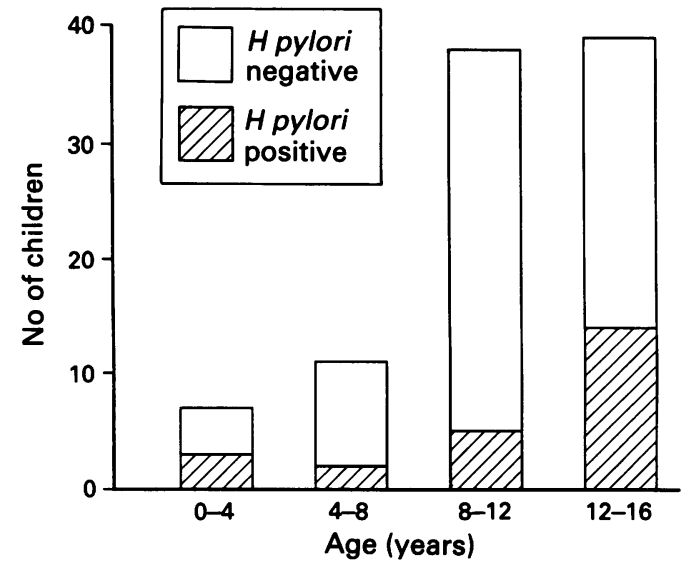

Figure 1 Age distribution of the study population.

colonisation (23 histology positive; one CLO positive, histology negative). Gastric histology was normal in the other 70 children and $H$ pylori was not detected on Giemsa staining or CLO test.

The CLO test was performed on 55 antral biopsies and was positive in 13 . All 13 biopsies had gastritis on histology and 12/13 were positive for $H$ pylori on Giemsa staining. The other 42 biopsies showed normal gastric histology and all were negative for $H$ pylori on histology.

\section{CLINICAL FEATURES}

The age range of the children studied and those with $H$ pylori associated gastritis is shown in figure $1 . H$ pylori gastritis was present mainly in older children and adolescents aged 8-16 years, but was present in five young children aged 9 months, 15 months, 2 years, and two aged 5 years. The sex distribution of $H$ pylori gastritis was 10 boys and 14 girls. A family history of peptic ulcer disease in first degree relatives was present in $6 / 24(25 \%) H$ pylori positive children with gastritis compared with $2 / 70$ (3\%) of those who were $H$ pylori negative, with normal gastric histology $(\mathrm{p}<0.003)$.

Although several children had multiple symptoms, the major symptom leading to endoscopy was recurrent abdominal pain. This was further subdivided into epigastric pain and

Social class distribution of $H$ pylori positive and $H$ pylori negative children

\begin{tabular}{|c|c|c|c|c|c|c|}
\hline & \multicolumn{3}{|c|}{ Non-manual classes } & \multicolumn{3}{|c|}{ Manual classes } \\
\hline & 1 & 2 & $3 N M$ & $3 M$ & 4 & 5 \\
\hline \multirow[t]{2}{*}{$H$ pylori positive } & 0 & 0 & 3 & 6 & 7 & 8 \\
\hline & \multicolumn{3}{|c|}{$3(12 \cdot 5 \%)$} & \multicolumn{3}{|c|}{$21(87 \cdot 5 \%)^{*}$} \\
\hline \multirow[t]{2}{*}{$H$ pylori negative } & 3 & 18 & 6 & 26 & 8 & 10 \\
\hline & \multicolumn{3}{|c|}{$27(38 \%)$} & \multicolumn{3}{|c|}{$44(62 \%)$} \\
\hline \multirow[t]{2}{*}{ Study population } & $\begin{array}{l}3 \\
(3 \cdot 1 \%)\end{array}$ & $\begin{array}{l}18 \\
(19 \%)\end{array}$ & $\begin{array}{l}9 \\
(9.5 \%)\end{array}$ & $\begin{array}{l}32 \\
(33 \cdot 7 \%)\end{array}$ & $\begin{array}{l}15 \\
(15 \cdot 8 \%)\end{array}$ & $\begin{array}{l}18 \\
(18 \cdot 9 \%)\end{array}$ \\
\hline & \multicolumn{3}{|c|}{$30(31 \cdot 6 \%)$} & \multicolumn{3}{|c|}{$65(68 \cdot 4 \%)$} \\
\hline \multirow{2}{*}{$\begin{array}{r}\text { West Yorkshire } \\
(1981 \text { census })\end{array}$} & $5 \%$ & $23 \%$ & $12 \%$ & $36 \%$ & $18 \%$ & $6 \%$ \\
\hline & \multicolumn{3}{|c|}{$40 \%$} & \multicolumn{3}{|c|}{$60 \%$} \\
\hline
\end{tabular}

${ }^{*}$ Significant difference between positive and negative groups $(\mathrm{p}<0 \times 02)$. central periumbilical pain. Epigastric pain was commoner in children with $H$ pylori gastritis, occurring in $13 / 24(54 \%)$, compared with $28 / 70$ $(40 \%)$ of those with normal histology, although this difference was not statistically significant $(\mathrm{p}=0.086)$. Central periumbilical abdominal pain was more common in $H$ pylori negative children with normal gastric histology, 27/70 (39\%), compared with $5 / 24(20 \%)$ of those with $H$ pylori positive gastritis, but this difference did not reach statistical significance $(p=0.069)$. Recurrent vomiting was the second most frequent symptom but was poorly discriminatory between the two groups, being present in 4/24 (17)\% and $12 / 70(17 \%)$ patients with and without $H$ pylori gastritis respectively. Other presenting symptoms in $H$ pylori positive children were haematemesis (one child), and melaena (one child). One child with $H$ pylori gastritis had refractory iron deficiency anaemia.

\section{SOCIAL CLASS}

The social class of the children studied was assigned according to the occupation of the head of the household using the registrar general's classification, and is shown in the table. For purposes of comparison, non-manual classes 1 , 2 , and $3 N M$ were grouped together and compared with manual classes $3 \mathrm{M}, 4$, and 5 . The social class distribution of the study population was broadly similar to that of the population of West Yorkshire, ${ }^{10}$ but there was a marked social class difference between $H$ pylori positive and negative children. Children of parents with manual occupations were overrepresented in the $H$ pylori positive gastritis group 21/24 (87.5\%) compared with $44 / 71(62 \%)$ in the $H$ pylor negative group $(\mathrm{p}<0.02)$, and no $H$ pylori positive child came from social class 1 or 2 .

\section{ENDOSCOPY}

Endoscopic abnormalities were present in 20/24 children with $H$ pylori gastritis. The commonest abnormality was antral nodularity (fig 2) found in 13/24; five children had antral erythema and gastric erosions were present in two. Duodenal ulcers were diagnosed in two children (aged 15 and 13 years): one was associated with gastric erosions and coexistent $H$ pylori gastritis on antral histology, the other was an isolated finding and was not associated with $H$ pylori gastritis. The principal endoscopic finding in the $H$ pylori negative, normal gastric histology group was macroscopic oesophagitis, present in $14 / 70$, and microscopic oesophagitis was found in a further eight on oesophageal biopsy.

\section{HISTOLOGY}

Of the 25 children with chronic gastritis, 22 had typical helicobacter associated chronic gastritis on histology. Three children showed the pattern of 'lymphocytic gastritis'. ": one of these had helicobacter on histological staining, and one was positive on CLO test, while all three had positive $H$ pylori serology. ${ }^{6}$ Thus $3 / 25$ (12\%) of children with chronic gastritis showed this special type of gastritis, a frequency higher than 


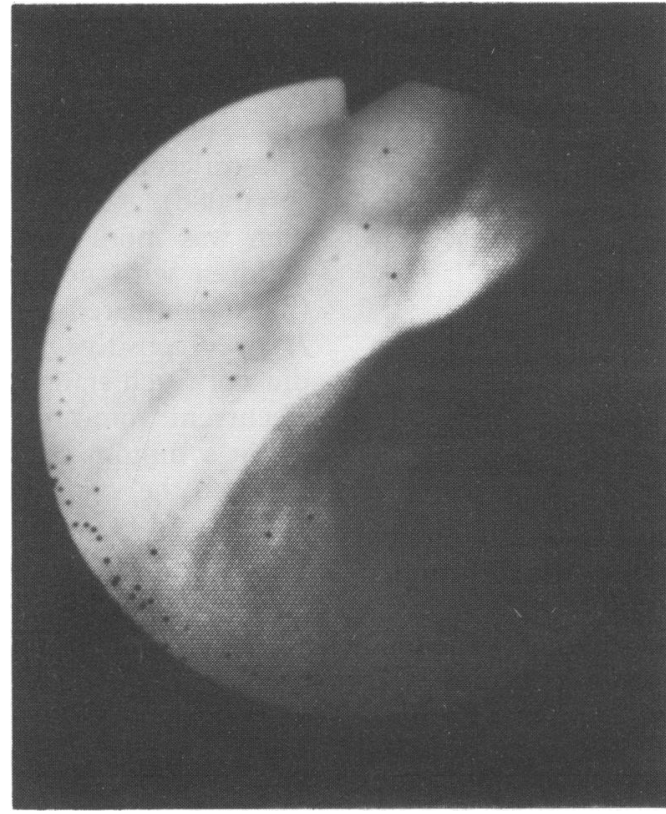

Figure 2 Antral nodularity seen at endoscopy in a child with $H$ pylori gastritis.

that seen in adults, where it is present in $2 \%$ of patients with chronic gastritis. ${ }^{11}$ None of the biopsy specimens showed reactive gastritis or any of the other special forms of gastritis recognised by the Sydney system.

The 22 children with helicobacter associated chronic gastritis (excluding cases of lymphocytic gastritis) were graded according to the Sydney system. All showed some increase in chronic inflammatory cells, and lymphoid follicles were present in biopsies from $12 / 22(55 \%)$ children (fig 3). The presence of 'activity' of chronic gastritis is assessed by the degree of neutrophil infiltration of the epithelium. This was present in specimens from $10 / 22(45 \%)$ children only, although it is characteristically present in adults with helicobacter gastritis. ${ }^{12}$

None of the biopsy specimens showed architectural irregularity to suggest there had been any atrophy of antral glands, and none of them showed intestinal metaplasia.

\section{RESULTS OF TREATMENT}

In the 12 children in whom antral biopsy specimens before and after treatment were studied, $H$ pylori eradication was achieved in

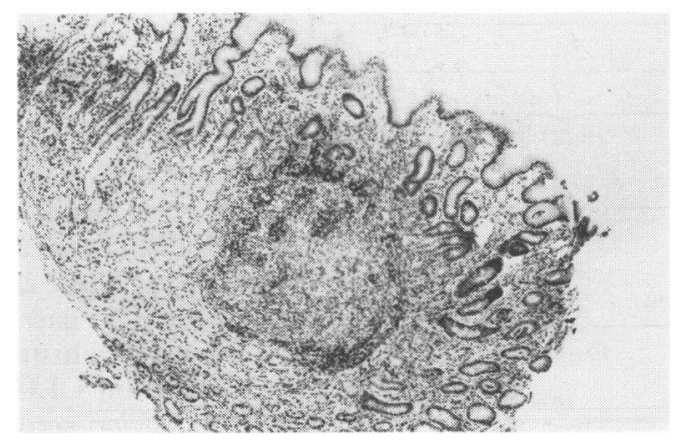

Figure 3 Lymphoid follicle in the antral mucosa of a child with $H$ pylori gastritis.

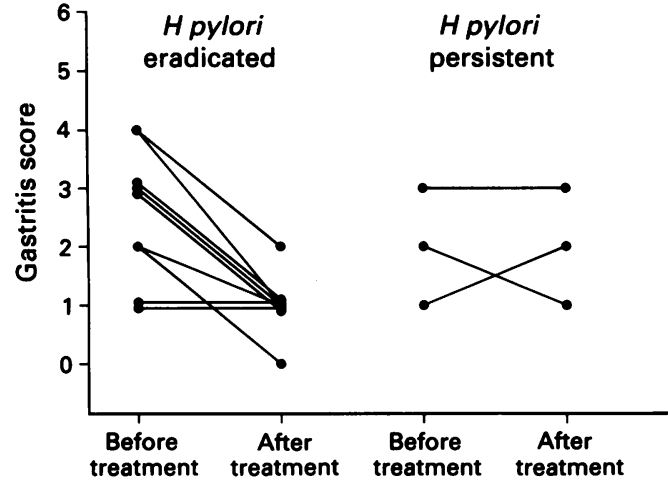

Figure 4 Severity of gastritis in antral biopsy specimens before and after treatment, showing significant reduction $(p<0.025)$ in gastritis score where $H$ pylori was eradicated.

$9 / 12(75 \%)$. Gastritis scores improved in the $H$ pylori eradication group from mean (SD) of $2.55(1.13)$ before treatment to $1(0.5)$ after treatment $(p<0.025)$ (fig 4). Symptoms resolved in seven children but were unchanged in two despite eradication of $H$ pylor $i$ and improvement in gastritis score. In the three children in whom $H$ pylori was not eradicated, gastritis score was not significantly altered, and all remained symptomatic. Six other children had identical treatment and all experienced an improvement in symptoms, but follow up endoscopy was declined by their parents. The 15 year old adolescent with duodenal ulcer and coexistent $H$ pylori gastritis was treated with tripotassium dicitratobismuthate and ampicillin at doses mentioned above, and ranitidine $150 \mathrm{mg}$ twice daily. Follow up endoscopy 11 months after presentation showed healing of the ulcer but mucosal biopsies were not obtained.

No child developed side effects from treatment. Bismuth concentrations ranged from 3 to $29 \mathrm{ng} / \mathrm{ml}$, mean $14.8 \mathrm{ng} / \mathrm{ml}$. Bismuth toxity is associated with concentrations above $50 \mathrm{ng} / \mathrm{ml}^{13}$

\section{Discussion}

This study confirms the findings of other workers that $H$ pylori gastritis is a significant cause of abdominal pain in the paediatric age group. ${ }^{3-5}$ The clinical profile of paediatric $H$ pylori gastritis that emerges from this study is of epigastric pain in the older child and adolescent (8-16 years) from a family of low socioecomonic status and a family history of peptic ulcer disease. However, we have found that $H$ pylori gastritis can occur in young children, and $20 \%$ of our cases were in children aged 5 years or younger. The bias towards low socioeconomic groups in $H$ pylori positive children suggests that social class is a factor in $H$ pylori acquisition in childhood. Children from higher social class groups appear to be less susceptible to $H$ pylori infection, and similar results have been found in adults in the United Kingdom. ${ }^{14}$ Although the reservoir of infection and modes of spread of $H$ pylori are not known, the social patterns are suggestive of faecal-oral transmission, and social class differences may reflect differences in sanitation and hygienic practices. $^{15}$ 
Positive endoscopic findings are common in children with $H$ pylori associated gastritis, especially antral nodularity. Lymphoid follicles were present in biopsies from $55 \%$ children; the presence of follicles was not correlated with the activity of the gastritis, nor the density of bacterial colonisation. As the antral mucosa in children is thinner than that in adults, it is likely that the presence of large lymphoid follicles accounted for the nodularity apparent on endoscopy.

Lymphocytic gastritis is an unusual pattern of inflammation in adults, but was seen rather more frequently in our paediatric biopsy specimens $(3 / 25)$. As in adults, these children showed serological evidence of $H$ pylori infection, although the bacteria were apparent on histology in only one of three children. The relationship between lymphocytic gastritis and $H$ pylori infection is still uncertain.

The precise indications for treatment and the optimal treatment regimen for children with $H$ pylori gastritis remain to be established. ${ }^{16} \mathrm{We}$ choose treatment with tripotassium dicitratobismuthate and ampicillin as this combination gave optimal results in a large adult study. ${ }^{17} \mathrm{We}$ achieved a $H$ pylori eradication rate of $75 \%$ and this is similar to other paediatric studies using a combination of ampicillin and bismuth preparations. ${ }^{5}{ }^{18}$ In adult studies better eradication rates have been achieved with dual therapy using a bismuth preparation and metronidazole, but there are problems with metronidazole resistance. ${ }^{19}$ Blood bismuth concentrations were measured because of concern about potential toxicity of bismuth preparations in children, and all were in the non-toxic range. Tripotassium dicitratobismuthate was well tolerated and no child developed side effects.

The discovery of $H$ pylori in 1983, and the subsequent demonstration of its role in gastroduodenal pathology, has been one the most exciting developments in gastroenterology in the past decade. Chronic abdominal pain in children has always been an important part of the paediatrician's workload. ${ }^{20}$ This study and others suggest a role for $H$ pylori in children with chronic abdominal pain and upper gastrointestinal symptoms. ${ }^{3-5}$ Although relatively uncommon in children, a strong association exists between $H$ pylori gastritis and duodenal ulceration. Furthermore, eradication of $H$ pylori has been shown to improve ulcer healing and to reduce ulcer relapse rate in children. ${ }^{21}$ The natural history of $H$ pylori gastritis is still being delineated, but present evidence suggests a slow progression to atrophic gastritis and gastric atrophy over a period of $20-40$ years. Atrophic gastritis and gastric atrophy are known to be precursor lesions for the development of gastric carcinoma, ${ }^{22}$ and this potential carcinogenicity of $H$ pylori makes it a significant pathogen in children.

Treatment with bismuth preparations and antibiotics can eradicate $H$ pylori and improve gastritis in about $75 \%$ of patients, but long term follow up and control studies are lacking. Recent reviews have sounded a note of caution about the indiscriminate treatment of $H$ pylori especially the risk of antibiotic resistance, both in children ${ }^{16}$ and in adults. ${ }^{19}$ Serological detection of $H$ pylori IgG antibodies is valuable in screening children with chronic abdominal pain for $H$ pylori gastritis, ${ }^{6}$ and perhaps endoscopy should be reserved for detection of associated duodenal ulcer disease. Treatment to eradicate $H$ pylori would then be justified in view of the role of $H$ pylori in duodenal ulcer healing and relapse. ${ }^{21}$ Further research remains to be done before we fully understand the precise role of $H$ pylori in children with chronic gastrointestinal symptoms, the indications for treatment, and the optimal agents.

1 Marshall BJ, Warren JR. Unidentified curved bacilli in the stomach of patients with gastritis and peptic ulceration. Lancet 1983; ;:1273-5.

2 Dixon MF. Campylobacter pylori and chronic gastritis. In: Rathbone BJ, Heatley RV, eds. Campylobacter pylori and gastroduodenal disease. Oxford: Blackwell Scientific Publications, 1989:106-16.

3 Drumm B, Sherman P, Cutz E, Karmali M. Association of Campylobacter pylori on the gastric mucosa with antra gastritis in children. N Engl F Med 1987;316:1557-61

4 Glassman MS, Schwarz SM, Medow MS, et al. Campylobacte pylori-related gastrointestinal disease in children: incidence and clinical findings. Dig Dis Sci 1989;34:1501-4.

5 De Giacomo C, Fiocca R, Villani L, et al. Helicobacter pylori infection and chronic gastritis: clinical, serological, and and colloidal bismuth subcitrate. $\mathcal{f}$ Pediatr Gastroenterol Nutr 1990;11:310-6.

6 Crabtree JE, Mahony MJ, Taylor JD, Heatley RV, Littlewood JM, Tomkins DS. Immune responses to Helicobacter py, Tomkins DS. Immune responses to Helicobacter pylori in children with

7 Gray SF, Wyatt JI, Rathbone BJ. Simplified techniques for identifying Campylobacter pyloridis. F Clin Pathol 1986 39:1279-80.

8 Price AB. The Sydney system: histological division. Journa of Gastroenterology and Hepatology 1991;6:209-22.

9 Rooney RC. Determination of bismuth in blood and urine. Analyst 1976;101:749-52.

10 Office of Population Censuses and Surveys. West Yorkshire county census report. London: HMSO, 1981.

11 Dixon MF, Wyatt JI, Burke DA, Rathbone BJ. Lymphocytic gastritis-relationship to Campylobacter pylori infection. f Pathol 1988;154:125-32.

12 Bayerdorffer E, Oertel H, Lehn N, et al. Topographic association between active gastritis and Campylobacter pylori sociation between active gastritis and Campy

13 Bader JP. The safety profile of De-Nol. Digestion 1987;37 suppl 2:53-9.

14 Sitas F, Forman D, Yarnell JWG, et al. Helicobacter pylori infection rates in relation to age and social class in a popula tion of Welsh men. Gut 1991;32:25-8.

15 Graham DY. Helicobacter pylori: its epidemiology and its role in duodenal ulcer disease. Fournal of Gastroenterology and Hepatology 1991;6:105-13.

16 Drumm B. Helicobacter pylori. Arch Dis Child 1990;65: 1278-82.

17 Rauws EAJ, Langenburg $W$, Houthoff $\mathrm{HJ}$, Zanen $\mathrm{HC}$ Tytgat GNJ. Campylobacter pyloridis-associated chronic active antral gastritis: a prospective study of its prevalence and the effects of antibacterial and antiulcer treatment. Gastroenterology 1988;94:33-40.

18 Drumm B, Sherman P, Chiasson D, Karmali M, Cutz E. Treatment of Campylobacter pylori-associated antral gasTreatment of Campylobacter pylori-associated antral gas-
tritis in children with bismuth subsalicylate and ampicillin. tritis in children with bismuth

19 Axon ATR. Helicobacter pylori therapy: effect on peptic ulcer disease. Fourna of Gastroenterology and Hepatology 1991:6:131-7.

20 Apley J. The child with abdominal pains. 2nd Ed. Oxford: Blackwell Scientific Publications. 1975.

21 Yeung CK, Fu KH, Yuen KY, et al. Helicobacter pylori and associated duodenal ulcer. Arch Dis Child 1990;65:1212-6.

22 Correa P. Is gastric carcinoma an infectious disease? $N$ Engl 7 Med 1991;325:1170-1. 